\title{
Artikel
}

\section{Wanneer je leven bepaald wordt door de wet}

\author{
- over handicap, regelgeving en identiteit
}

Mr. drs. E. Dijkstra*

\section{Inleiding}

De wet bepaalt voor ons allemaal, tot op zekere hoogte, welke mogelijkheden wij hebben bij het inrichten van ons leven. Daarmee beïnvloedt zij ook wat wij verwachten van het leven, waar wij naar streven en - uiteindelijk - wie wij zijn. ${ }^{1}$ Dit geldt nog sterker voor mensen met een functiebeperking, zowel verstandelijk als lichamelijk, die voor hun meest basale behoeften vaak volledig afhankelijk zijn van de wettelijk geregelde sociale voorzieningen. ${ }^{2}$ Zodoende heeft het mens- en maatschappijbeeld in de wet - oftewel de noties betreffende hetgeen een menswaardig leven vereist en in hoeverre de maatschappij hiervoor verantwoordelijk is - een enorme invloed op de verwachtingen, het streven en de identiteit van deze groep. Aldus beinvloedt het mens- en maatschappijbeeld in de wet niet alleen of er voldoende voorzieningen zijn voor mensen met een functiebeperking, maar ook de denkkaders van de discussie wanneer mensen, met en zonder een functiebeperking, opkomen tegen ervaren tekortkomingen in deze voorzieningen. ${ }^{3}$

In dit essay zal verkend worden hoe recentelijk zowel de voorzieningen voor mensen met een functiebeperking verschraalden, als de discussie over de verantwoorde-

* Mr. drs. E. (Erwin) Dijkstra is als docent/onderzoeker verbonden aan het Instituut Metajuridica van de Rechtswetenschap van de Faculteit der Rechtsgeleerdheid van de Universiteit Leiden.

1. B. Barry, Why social justice matters, Cambridge: Polity Press 2005, p. $72-73$.

2. M.C. Nussbaum, Frontiers of justice: disability, nationality, species membership, Cambridge: Harvard University Press 2006, p. 73, 99, 415

3. Nussbaum 2006, p. 4. lijkheid van de maatschappij voor mensen met een functiebeperking gelimiteerd werd, ten gevolge van de aannames van de wetgever. Hiertoe illustreer ik eerst kort hoe aannames in de wet komen. Vervolgens kijk ik naar de veranderingen in het mens- en maatschappijbeeld, waarvan de sociale zekerheid uitgaat. Deze veranderingen zullen we tot slot weerspiegeld zien in de beperking van het recht op individuele assistentie en hulpmiddelen, die werd ingeluid met de Wet maatschappelijke ondersteuning 2015 (Wmo 2015), en het beperkte blikveld van het maatschappelijk debat rondom de Wajong en de Participatiewet.

\section{Metafysica uit de steentijd?}

Het is wellicht een open deur, maar wetten en regels komen niet in een vacuüm tot stand, laat staan dat zij als zodanig functioneren. ${ }^{4}$ Sterker nog, er kan worden gesteld dat, naast hun technische betekenis, wetten, juridische concepten en doctrines mede gebaseerd zijn op theoretische en empirische overtuigingen over feitelijke en normatieve aspecten van de wereld. ${ }^{5}$ Regels reflecteren daarmee - al of niet achterhaalde - filosofische ideeen, algemene overtuigingen en waardeoordelen. ${ }^{6}$ Ondanks de neutrale taal van het recht, maakt de wet dus ideologische keuzes die sociaal noch politiek neu-

H.L.A. Hart, The concept of law, Oxford: Clarendon Press 1961, p. 85, 101, 114.

5. P. Cserne, 'Objectivity and the law's assumptions about human behaviour', in: J. Husa \& M. van Hoecke (red.), Objectivity in law and legal reasoning, Oxford: Hart Ltd. 2013, p. 171.

6. Cserne 2013, p. 173 
traal zijn. ${ }^{7}$ Dergelijke keuzes versterken zichzelf, aangezien de normen in de wet mede bepalen hoe het algemene publiek over zaken denkt en zij op hun beurt weer degenen kiezen die wetten en beleid vormgeven. ${ }^{8}$ Als gevolg hiervan kan bijvoorbeeld een bepaald groepsbelang systematisch achtergesteld worden bij de behoeften van het gros van de mensen. ${ }^{9}$ Daarom is het belangrijk om de aannames in de wet te reconstrueren en tegen het licht te houden: kloppen de feitelijke aannames wel en zijn de normatieve aannames wenselijk? ${ }^{10}$ Want voor hetzelfde geld baseert de wet zich op een 'metafysica uit de steentijd'. ${ }^{11}$ Deze discussie over de aannames in de wet is, zoals gezegd, van groot belang voor een belangrijk deel van de mensen met een functiebeperking. Er is namelijk een breed scala aan feitelijke en normatieve aannames beschikbaar over de wenselijke maatschappelijke positie van mensen met een functiebeperking. De keuzes van de wetgever in dezen zullen, door de afhankelijkheid van een groot deel van deze groep, daarom goeddeels de kwaliteit van het leven met een functiebeperking bepalen.

Over het leven dat mensen met een functiebeperking zouden moeten kunnen leiden en in hoeverre de maatschappij dit mogelijk dient te maken, bestaan dus verschillende aannames. Het Verdrag inzake de rechten van personen met een handicap (VN-verdrag Handicap), dat Nederland in 2016 ratificeerde, neemt bijvoorbeeld het sociale model van handicap als uitgangspunt. ${ }^{12}$ Dit model gaat ervan uit dat de maatschappij is ingericht op de noden van het merendeel van de bevolking, en daarom niet noodzakelijkerwijs aansluit op de behoeften van mensen met een functiebeperking. ${ }^{13}$ Dit betekent niet dat de lichamelijke en verstandelijke last van een functiebeperking er niet toe doet, maar dat de maatschappelijke achterstelling of handicap - die mensen met een functiebeperking ervaren - het gevolg is van menselijke keuzes en niet inherent aan een functiebeperking. ${ }^{14}$ Hoge stoepen houden bijvoorbeeld onvoorzichtige voetgangers onder auto's vandaan, maar vormen een dage-

7. D. Kennedy, A critique of adjudication: fin de siècle, Cambridge: Harvard University Press 1997, p. 18-19, 28, 33; A. Macintyre, After virtue: a study in moral theory, Londen: Bloomsbury 2017, p. 286-295.

8. J.R. Searle, The construction of social reality, New York: Free Press 1995, p. 88, 127-147; K. Vuyk, Oude en nieuwe ongelijkheid: over het failliet van het verheffingsideaal, Utrecht: Klement 2017, p. 24-25.

9. Kennedy 1997, p. 41, 57

10. Cserne 2013, p. 183-184; H.L.A. Hart, Punishment and responsibility: essays in the philosophy of law, Oxford: Oxford University Press 1968, p. 88, 262.

11. P. Cserne, "Between the "metaphysics of the stone age" and the "brave new world": H.L.A. Hart on the law's assumptions about human nature', in: M. Jovanović \& B. Spaić (red.), Jurisprudence and political philosophy in the 21st century: reassessing legacies, Frankfurt: Peter Lang 2012, p. 72.

12. T. Degener, 'A new human rights model of disability', in: V. della Fina, R. Cera \& G. Palmisano (red.), The United Nations Convention on the Rights of Persons with Disabilities: A Commentary, Cham: Springer 2017, p. 42.

13. T. Shakespeare, 'The social model of disability', in: L.J. Davis (red.), The disability studies reader, New York: Routledge 2017, p. 190-199.

14. L. Crow, 'Including all of our lives: renewing the social model of disability', in: C. Barnes \& G. Mercer (red.), Exploring the divide: illness and disability, Leeds: Disability Press 1996, p. 58. lijks obstakel voor rolstoelgebruikers. ${ }^{15}$ Door een dergelijk gebrek aan toegankelijkheid is de laatste groep beperkt in de locaties waar zij kunnen werken en wordt de hoeveelheid tijd en energie die het forenzen hen kost, vergroot. ${ }^{16}$ Vanwege dergelijke achterstellingen zouden mensen met een functiebeperking, volgens de doelen van het VN-verdrag Handicap, door de maatschappij gefaciliteerd moeten worden om - zo veel mogelijk hun eigen leven in te richten en zelfstandige keuzes te maken op gelijke voet met hun medeburgers, met wier noden het ontwerp van de maatschappij reeds rekening hield. ${ }^{17}$

Dit is echter niet het mens- en maatschappijbeeld dat we heden ten dage in de wet tegenkomen in het Westen, Nederland incluis. In plaats daarvan zien we, kort gezegd, het idee van de maatschappij als een sociaal contract dat gesloten is voor wederzijds voordeel, waarbij het leven van mensen tot op grote hoogte geacht wordt maakbaar te zijn. ${ }^{18}$ Met een dergelijk maatschappijbeeld zal de inrichting van de maatschappij vooral geënt zijn op de mensen die op bepaalde afgebakende manieren bijdragen - zoals de spreekwoordelijke 'hardwerkende belastingbetaler'. ${ }^{19}$ Mensen met een functiebeperking, die niet (gedeeltelijk) kunnen bijdragen op een manier die als verdienstelijk wordt beschouwd, verworden daarmee tot maatschappelijke ontvangers. ${ }^{20}$ Daarmee vormen zij - in deze optiek althans - een last die de productieve groep mensen dient te dragen. ${ }^{21} \mathrm{Zo}$ worden veel mensen met een functiebeperking als maatschappelijke uitzondering veroordeeld tot een onzekere afhankelijkheid van regelingen met een liefdadigheidskarakter. ${ }^{22}$ Dit liefdadigheidskarakter - en daarmee de wisselvalligheid van deze arrangementen - wordt verder versterkt door het prevalente mensbeeld, dat uitgaat van makbaarheid. Deze maakbare mens is een product van de toenemende invloed van de meritocratische gedachte, oftewel de definitie van verdienste als talent, voornamelijk gezien als IQ plus inzet. ${ }^{23}$ Dankzij de emancipatiemotor die algemeen toegankelijk onderwijs vormt, is volgens deze gedachte - een goede baan bereikbaar voor

15. Nussbaum 2006, p. 109, 113, 116-17.

16. K. Lippert-Rasmussen, Born free and equal? A philosophical inquiry into the nature of discrimination, Oxford: Oxford University Press 2014, p. 39.

17. E. Dijkstra, 'De coronacrisis noopt tot meer expliciete aandacht van de Nederlandse staat voor het VN-verdrag Handicap', NTM/NJCM-Bulletin 2020, afl. 45, p. 378.

18. Nussbaum 2006, p. 130, 222.

19. G. Herderscheê, 'Het dreigende einde van de verzorgingsstaat', de Volksrant 12 mei 2018, Zaterdag, p. 12-14.

20. M. Canoy \& I. Robeyns, 'Vernederen is het nieuwe participeren', NRC Handelsblad 4 juni 2018, Opinie, p. 18; T.M. Scanlon, The diversity of objections to equality, Kansas: The University of Kansas Press 1996, p. 5.

21. Nussbaum 2006, p. 4, 135, 137-138; C.A. de Kam \& J.H.M. Donders, Onzekere zekerheden: de Nederlandse verzorgingsstaat op weg naar 2025, Den Haag: Willem Drees Stichting voor Openbare Financiën 2014, p. 48

22. Nussbaum 2006, p. 108-109.

23. P. de Beer, 'Meritocratie: op weg naar een nieuwe klassensamenleving?', in: P. de Beer \& M. van Pinxteren (red.), Meritocratie: op weg naar een nieuwe klassensamenleving?, Amsterdam: Amsterdam University Press 2016, p. 10 (verder: De Beer 2016a). 
iedereen die het verdient. ${ }^{24}$ Een dergelijke nadruk op verdienste verandert de notie van gerechtvaardigde verschillen. ${ }^{25}$ Voor iedereen zijn er kansen, dus ook vanaf een minderbedeelde positie kan je veel bereiken. De makkbare mens heeft immers zijn eigen lot in handen. ${ }^{26}$ Daarom moeten de minstbedeelden in toenemende mate het recht op overheidssteun verdienen. ${ }^{27}$ Het is deze consequentie van het beschreven mens- en maatschappijbeeld, die we gereflecteerd zien in de teloorgang van de sociale zekerheid.

\section{Het primaat van de reguliere arbeidsmarkt}

Dat men voor het hierboven beschreven mens- en maatschappijbeeld koos en de sociale zekerheid hierop inrichtte, was niet onvermijdelijk. Het grote bouwwerk van de sociale zekerheid in de jaren vijftig en zestig draaide immers juist om statusbehoud en het voortzetten van de voormalige levensstijl, door bijvoorbeeld het verloren arbeidsvermogen financieel te ondervangen. ${ }^{28}$ Dit was een recht van iedereen in nood - tot wanneer en indien men weer op eigen benen kon staan. ${ }^{29}$ Deze maatschappelijke verantwoordelijkheid voor de risico's waaraan een mensenleven onderhevig is, werd steeds verder uitgebreid totdat eind jaren tachtig het aantal ontvangers en de kosten volgens opeenvolgende regeringen uit de hand liepen. ${ }^{30}$ Daarom werden zowel de regelingen versoberd als de uitstroom gestimuleerd en de toegang beperkt. ${ }^{31}$ Onder invloed van het tot wasdom gekomen maakbaarheidsdenken werden de gevolgen van een groot aantal risico's, die het publieke domein tot dan toe herverdeelde, teruggelegd bij het individu. ${ }^{32}$ Der-

24. Vuyk 2017, p. 166-167; De Beer 2016a, p. 17-18

25. M.J. Sandel, The tyranny of merit: what's become of the common good?, Londen: Allen Lane 2020, p. 25, 59, 63, 96

26. Vuyk 2017, p. 169; R. Claassen, Het eeuwige tekort: een filosofie van de schaarste, Amsterdam: Ambo 2004, p. 120

27. J. Elshout, E. Tonkens \& T. Swierstra, 'Meritocratie als aanslag op het zelfrespect van verliezers', in: P. de Beer \& M. van Pinxteren (red.), Meritocratie: op weg naar een nieuwe klassensamenleving?, Amsterdam: Amsterdam University Press 2016, p. 227.

28. P. van Lieshout, 'De toekomst van de sociale (on)zekerheid', in: P. van Lieshout (red.), Sociale (on)zekerheid: de voorziene toekomst, Amsterdam: Amsterdam University Press 2016, p. 8-9.

29. E. Tonkens \& L. Verplanke, 'Sociale zekerheid: een gelaagd begrip. Materiële, emotionele en relationele zekerheid in de eenentwintigste eeuw', in: P. van Lieshout (red.), Sociale (on)zekerheid: de voorziene toekomst, Amsterdam: Amsterdam University Press 2016, p. 196.

30. K. Goudswaard, 'Hervorming van de arbeidsongeschiktheidsregelingen', in: G. Jehoel-Gijsbers (red.), Op weg naar een inclusieve arbeidsmarkt, Den Haag: Centraal Planbureau 2011, p. 21

31. Van Lieshout 2016, p. 22

32. Van Lieshout 2016, p. 22; K. Putters \& S. Hoff, 'Sociale onzekerheid', in: P. van Lieshout (red.), Sociale (on)zekerheid: de voorziene toe komst, Amsterdam: Amsterdam University Press 2016, p. 44; P. de Beer, 'De grote golf van het sociale stelsel', in: P. van Lieshout (red.) Sociale (on)zekerheid: de voorziene toekomst, Amsterdam: Amsterdam University Press 2016, p. 74 (verder: De Beer 2016b). Een belangrijk kantelpunt vormde het navolgende rapport: F.W. Rutten et al., Een werkend perspectief: arbeidsparticipatie in de jaren '90 - WRR-rapport 1990, Den Haag: Sdu Uitgeverij 1990. gelijke hervormingen trachtten het zelfredzame individu te activeren om het meeste te maken van hun (resterende) arbeidsvermogen, vooraleer zij wellicht in aanmerking zouden komen voor publieke voorzieningen. ${ }^{33}$ En hiermee zien we de triomf van het hierboven beschreven mens- en maatschappijbeeld, waar de wet heden ten dage van uitgaat: steun is voorwaardelijk en moet verdiend worden, zoals '[past] bij het waardepatroon van veel Nederlanders'. ${ }^{34}$ De bijbehorende activerende mechanismen leunen dan ook op het idee dat het overgrote deel van de mensen zelfredzaam genoeg is om wat van hun leven te maken, hooguit is er een duwtje in de rug nodig. ${ }^{35}$

De terugtrekking van het publieke domein en het privatiseren van risico's is funest voor mensen die niet zelfredzaam zijn en geen alternatief hebben. ${ }^{36}$ Als levens niet tot een succes zijn te kneden wegens omstandigheden buiten hun bereik - zoals functiebeperkingen komen mensen zo letterlijk buiten de doelen van het maatschappelijke vangnet te staan. ${ }^{37}$ Deze uitsluiting is recentelijk nog sterker geworden met de participatiemaatschappij als praktische implementatie van het prevalente mens- en maatschappijbeeld. ${ }^{38}$ In de participatiemaatschappij is het primaat van de reguliere arbeidsmarkt, als enige manier om volwaardig deel te nemen aan de maatschappij, nog scherper afgetekend. ${ }^{39}$ Daarnaast wordt de steun voor mensen van wie alsnog verondersteld wordt dat zij op die manier niet in hun behoeften kunnen voorzien, zo veel mogelijk uitbesteed aan hun persoonlijke netwerk. Zodoende zijn er dus nog wel vangnetten, maar de omstandigheden die toegang geven tot dergelijke steun worden steeds verder gereduceerd. Daarenboven worden ook de voorzieningen zelf steeds verder beperkt en wordt de steun die er beschikbaar is allengs aan meer voorwaarden gebonden, zoals een tegenprestatie, het eerder genoemde beroep op het eigen netwerk en eisen aan de vermogenspositie van gezinsleden. ${ }^{40}$

We lijken dus ver te zijn verwijderd van een maatschappij wier taak het is om ook voor mensen met een functiebeperking de eigen regie over hun leven mogelijk te maken; oftewel het mens- en maatschappijbeeld van het VN-verdrag Handicap. Toch zou een dergelijke conclusie de verantwoordelijke politici verbazen, juist vanwege

33. R. van der Veen, 'Sociale zekerheid in een open samenleving', in: P. van Lieshout (red.), Sociale (on)zekerheid: de voorziene toekomst, Amsterdam: Amsterdam University Press 2016, p. 93; De Beer 2016b, p. 64.

34. Van Lieshout 2016, p. 10.

35. Van der Veen 2016, p. 95; Van Lieshout 2016, p. 10; De Beer 2016b, p. 68.

36. Vuyk 2017, p. 228

37. Putters \& Hoff 2016, p. 46, 48

38. C. Steinfeld, 'Lerende professionals in wijkteams', in: A.J. Kruiter, F. Bredewold \& M. Ham, Hoe de verzorgingsstaat verbouwd wordt: kroniek van een verandering, Amsterdam: Van Gennep 2016, p. 81; De Kam \& Donders 2014, p. 221.

39. Herderscheê 2018, p. 12-14.

40. P. van Echtelt, 'Beleidstheorie achter de Participatiewet', in: P. van Echtelt et al, Eindevaluatie van de Participatiewet, Den Haag: Sociaal en Cultureel Planbureau 2019, p. 58-63; G. Herderscheê, "Tegen wie niet wil werken moet ik streng zijn", de Volkskrant 21 november 2019, Ten eerste, p. 11 
hun andere mens- en maatschappijbeeld. In de memorie van toelichting van de Participatiewet wordt bijvoorbeeld benadrukt dat een baan op de reguliere arbeidsmarkt juist de beste sociale zekerheid is en dat het individu op deze manier de ruimte krijgt om zichzelf te ontplooien zonder al te veel paternalistische overheidsbemoeienis. ${ }^{41}$ Als het individu de reguliere arbeidsmarkt op kan worden geactiveerd, zou dit de onafhankelijkheid van mensen met functiebeperking naderbij kunnen brengen, is de redenering. ${ }^{42}$ Men kan zich echter afvragen of deze activerende elementen niet juist de beoogde zelfstandigheid in de weg staan en of de extra verantwoordelijkheid en de fijnmazigheid van de relevante regels - mede zo vormgegeven om profiteurs te ontmoedigen - niet erg veel vragen van een groot deel van de mensen met een functiebeperking; zij hebben immers vaak al minder tijd en energie en gewoonlijk een kleiner persoonlijk netwerk. ${ }^{43}$ De praktische veranderingen in de Wmo en de grote groepen mensen die binnen de geaccepteerde kaders van de discussie rond de Wajong en de Participatiewet vergeten worden, kunnen deze bezwaren verder verduidelijken.

\section{Kunstmatige schaarste}

In theorie zou de Wmo bij uitstek kunnen bijdragen aan de doelen van het VN-verdrag Handicap. Deze wet heeft namelijk de intentie om een inclusieve samenleving te realiseren en de zelfredzaamheid en participatie van mensen met een functiebeperking te bevorderen. ${ }^{44}$ In dat kader kan men aan deze groep van overheidswege individuele assistentie en hulpmiddelen verstrekken. ${ }^{45}$ Zoals hierboven al werd aangegeven, lijken de recente wijzigingen van deze wet - en de aannames over mens en maatschappij achter deze wijzigingen - echter volwaardige maatschappelijke deelname juist te bemoeilijken en in die zin een inclusieve samenleving op de lange baan te schuiven. ${ }^{46}$ Waar de oude Wmo de nadruk legde op de eigen regie - het inrichten van het eigen leven en de steun die hiervoor nodig was, draait de Wmo 2015 namelijk meer om het terugleggen van de verantwoorde-

41. Kamerstukken // 2011/12, 33161, nr. 3, p. 1; C. van Ewijk, 'Kapitaalopbouw voor Zorg, zekerheid en pensioen', in: P. van Lieshout (red.), Sociale (on)zekerheid: de voorziene toekomst, Amsterdam: Amsterdam University Press 2016, p. 114

42. C. Kammer \& M. Beunderman, 'Wederdienst voor bijstand omstreden', NRC Handelsblad 22 november 2019, In het nieuws, p. 2

43. Putters \& Hoff 2016, p. 54; Tonkens \& Verplanke 2016, p. 189-193; Sjors van Beek, 'Eigen kracht, je moet het maar hebben', in A.J. Kruiter, F. Bredewold \& M. Ham, Hoe de verzorgingsstaat verbouwd wordt kroniek van een verandering, Amsterdam: Van Gennep 2016, p. 138; A.W.A. Boot et al., Weten is nog geen doen: een realistisch perspectief op zelfredzaamheid - WRR-rapport nr. 97, Den Haag: Wetenschappelijk Raad voor het Regeringsbeleid 2017, p. 145; De Kam \& Donder 2014, p. 47, 207-208; J. Witteman, 'De grenzeloze jacht op de bijstandsfraudeur', de Volkskrant 16 juni 2018, Zaterdag, p. 2-6.

44. L. van der Ham et al., De Wmo 2015 in de praktijk, Den Haag: Sociaal en Cultureel Planbureau 2018, p. 21.

45. I.A.M. Boetzelaer-Gulyas, Basisboek sociale zekerheid 2020, Deventer: Wolters Kluwer 2020, p. 132.

46. Kamerstukken // 2013/14, 33841, nr. 3, p. 119 lijkheid voor dergelijke steun bij de burgers zelf. ${ }^{47}$ Dit is vooral duidelijk bij de mogelijkheid voor individuele assistentie, een hulpmiddel of andere maatwerkvoorzieningen. De trend lijkt - kort gezegd - minder, duurder en moeilijker. ${ }^{48}$ Voor de overige noden dient men uit te gaan van de eigen kracht en de hulp die men van het eigen netwerk kan verwachten; de Wmo 2015 is in die zin louter een noodventiel. ${ }^{49}$ De minst zelfredzame groep - die de meeste hulp nodig heeft, de minste verdiencapaciteit bezit om hier zelf in te voorzien en het minst slagvaardige persoonlijke netwerk om zich heen heeft weten te verzamelen - komt zo verder achterop. ${ }^{50}$ Een ander aspect betreft de uitvoering. Net als bij veel andere socialezekerheidsregelingen tracht men deze voormalige overheidstaak zo veel mogelijk te privatiseren; de uitvoering van deze privatisering is daarnaast gedecentraliseerd. ${ }^{51}$ De gemeenten zijn daarmee verantwoordelijk geworden voor de inkoop van de ondersteuning en hulpmiddelen. ${ }^{52}$ Ondanks recentelijk gesloten gemeentelijke convenanten lijkt hier rechtsongelijkheid te kunnen ontstaan. ${ }^{53}$ Per gemeente is de steun die men kan verwachten, naar het zich laat aanzien, namelijk verschillend en ook hier zijn de meest beperkte mensen de groep zonder alternatief voor publieke voorzieningen - de dupe. ${ }^{54}$

\section{Een ingekaderde discussie}

Het is ook de groep waarvan de omstandigheden het minst aansluiten bij de burger die bijdraagt aan de maatschappij via de reguliere arbeidsmarkt, die ondergesneeuwd raakt in de discussie rond de Wajong en de Participatiewet. ${ }^{55}$ Dit ondergesneeuwd raken heeft twee aspecten: wie er kunnen protesteren - dus van wiens zorgen het waarschijnlijker is dat zij worden meegenomen door de wetgever - en vanuit welke aannames en mogelijkheden de discussie over de benodigde voor-

47. Kamerstukken I/ 2013/14, 33841, nr. 3, p. 1-2; Boetzelaer-Gulyas 2020, p. 132, 134; Van der Ham et al. 2018, p. 20.

48. Boetzelaer-Gulyas 2020, p. 139-140.

49. Kamerstukken I/ 2013/14, 33841, nr. 3, p. 27; Boetzelaer-Gulyas 2020, p. 132; K. Bos, 'Wieltjes waren nergens te vinden', NRC Handelsblad 4 april 2017, Binnenland, p. 11.

50. S. Koker, 'Gezondheid en zorg', in: R. Bijl, J. Boelhouwer \& A. Wennekers (red.), De sociale staat van Nederland, Den Haag: Sociaal en Cultureel Planbureau 2017, p. 204-206; R. Bijl, A. Wennekers \& B. Boelhouwer, 'Nederland van 1990 tot nu - hoofdlijnen en slotbeschouwing', in: R. Bijl, J. Boelhouwer \& A. Wennekers (red.), De sociale staat van Nederland, Den Haag: Sociaal en Cultureel Planbureau 2017, p. 380.

51. Van der Ham et al. 2018 , p. 20

52. Boetzelaer-Gulyas 2020, p. 133

53. Boetzelaer-Gulyas 2020, p 133, 141-142.

54. Raad voor de Rechtspraak, 'Wetsadvisering concept wetsvoorstel maatschappelijke ondersteuning 2015', Wetgevingsadvies 4 september 2013, p. 3; C. Huisman, 'Mijn hulphond kan niet poetsen', de Volkskrant 4 april 2019, Ten eerste, p. 11.

55. Elshout, Tonkens \& Swierstra 2016, p. 209-233. Veel mensen met een functiebeperking zijn sinds 2015 naar de Participatiewet overgeheveld, die aanpalend versoberd werd, zie: G. Herderscheê, 'Analyse Participatiewet: arbeidsgehandicapten genieten steeds minder bescherming', de Volkskrant 15 januari 2015, Ten eerste, p. 13. 
zieningen voor mensen met een functiebeperking wordt gevoerd.

Er zijn grofweg twee groepen die over het algemeen weinig van zich laten horen. Ten eerste is er de groep zeer zwaar verstandelijk en lichamelijk beperkte mensen, wier noden en verwachtingen van het leven niet onmiddellijk duidelijk zijn, maar wel kunnen worden vastgesteld door professionals. ${ }^{56}$ Ten tweede is er de groep die niet volledig afhankelijk is en tenminste gedeeltelijk in staat om een eigen levensverwachting te formuleren, maar die nog steeds moeite heeft met onafhankelijk leven, sociale relaties en werk. ${ }^{57}$ De manier waarop deze beide groepen kunnen en willen bijdragen - meestal niet op de reguliere arbeidsmarkt - past niet in het huidige mens- en maatschappijbeeld waar de sociale zekerheid van uitgaat. ${ }^{58}$ Toch zien we dat deze groepen zich meestentijds neerleggen bij hun maatschappelijke positie, zij missen veelal de tijd, de mogelijkheid en de energie om zich hiertegen te verzetten. ${ }^{59}$

Degenen die daadwerkelijk opkomen tegen de verschraling van de voorzieningen voor mensen met een functiebeperking - de mensen die nog steeds worstelen met hun eigen functiebeperking, maar desalniettemin functioneren op een hoger niveau - proberen op bewonderenswaardige wijze ook de belangen van deze twee groepen voor het voetlicht te brengen. ${ }^{60}$ Toch sluit de beeldvorming rondom hun protesten meestal aan bij het mens- en maatschappijbeeld waar de wetgever eertijds van uitging. Zodoende handelt een belangrijk deel van de discussie rondom de Wajong en de Participatiewet over de positie van het relatief kleine aantal mensen met een functiebeperking dat nog (gedeeltelijk) op de reguliere arbeidsmarkt werkt, al of niet met een eerder voltooide opleiding. ${ }^{61}$ En deze discussie vertaalt zich in aandacht van de regering en het parlement, waarbij de aanpassingen die we bijvoorbeeld zagen bij de recente hervormingen van beide wetten vooral op deze groep

56. L.P. Francis \& A. Silvers, 'Liberalism and individual scripted ideas of the good: meeting the challenge of dependent agency', Social theory and practice, 2007, afl. 33, p. 316-318, 331.

57. C. Claes, S. Vandevelde \& J. van Loon, 'Participeren aan de samenleving', in: B. Maes, C. Vlaskamp \& A. Penne (red.), Ondersteuning van mensen met ernstige meervoudige beperkingen: handvatten voor een kwaliteitsvol leven, Den Haag/Leuven: Acco 2011, p. 75-77; De Kam \& Donders 2014, p. 209.

58. P. van Echtelt, K. Sadiraj \& S. Hoff, 'Jonggehandicapten met arbeidsvermogen', in: P. van Echtelt et al, Eindevaluatie van de Participatiewet, Den Haag: Sociaal en Cultureel Planbureau 2019, p. 118, 120-121; Francis \& Silvers 2007, p. 332; Nussbaum 2006, p. 104-105.

59. W. Boele \& H. Bosselaar, 'Haagse droom helpt mens met beperking niet', Trouw 1 december 2018, Opinie, p. 28-29; E. Heinze, 'Cumulative jurisprudence and hate speech: sexual orientation and analogies to disability, age, and obesity', in: I. Hare \& J. Weinstein (red.), Extreme speech and democracy, Oxford: Oxford University Press 2009, p. 276

60. T. Heijmans, 'Sociale werkplaats', de Volkskrant 15 januari 2018, Opinie \& Debat, p. 25; G. Herderscheê, 'Duizenden Wajongers belanden onder het bestaansminimum', de Volkskrant 16 juli 2018, Ten eerste p. 12; Miep Smitsloo, 'Ik stort me vaak maar gewoon in het diepe', Leidsch Dagblad 8 augustus 2020, Regio, p. 10

61. G. Herderscheê, 'Lager loon gehandicapten stuit op fel verzet', de Volkskrant 27 april 2018, Ten eerste, p. 2; G. Herderscheê, 'Ook gehandicapte houdt recht op minimumloon', de Volkskrant 7 september 2018, Ten eerste, p. 2. gericht waren. ${ }^{62}$ Aldus blijven de belangen van mensen met een functiebeperking die minder zichtbaar en (relatief) minder zelfredzaam zijn niet alleen een ondergeschoven kindje, maar wordt deze groep ook disproportioneel getroffen door de meeste hervormingen; omdat zij minder invloed uitoefenen en omdat de aannames van het onderliggende mens- en maatschappijbeeld, die hen het hardste raken, nog te weinig worden bevraagd. ${ }^{63}$

\section{Conclusie en vooruitblik}

Nog meer dan voor de meeste Nederlanders bepaalt de wet voor veel mensen met een functiebeperking de kaders waarbinnen zij kunnen en ervaren te leven. In het huidige mens- en maatschappijbeeld waarvan de sociale zekerheid uitgaat, is er voor grote groepen mensen met een functiebeperking eigenlijk geen plaats. $\mathrm{Zij}$ worden gezien als maatschappelijke ontvangers in plaats van deelnemers en de voorzieningen die velen van hen nodig hebben voor hun basale behoeften, worden navenant als een vorm van liefdadigheid behandeld, waar men gerust iets voor terug kan vragen. Het maatschappelijke debat gaat hier, naar alle waarschijnlijkheid, weinig aan veranderen. Dit wordt namelijk goeddeels binnen hetzelfde denkkader gevoerd. Toch zal een omslag overwogen moeten worden. Nederland heeft zich immers vastgelegd op het VN-verdrag Handicap, waarvan het achterliggende doel de matschappelijke deelname van alle mensen met een functiebeperking op gelijke voet met hun medeburgers behelst, wat mede inhoudt dat zij de mogelijkheid hebben om hun eigen leven in te richten. Deze situatie kan gradueel worden bereikt, maar onderwijl mogen de verdragsstaten niet tegen de verplichtingen van het verdrag ingaan. ${ }^{64}$ En dat maakt de hierboven beschreven ontwikkelingen in de sociale zekerheid, zoals de verschraling van de Wmo 2015 en de kaders van de discussie rond de Wajong en de Participatiewet, zo zorgelijk. De aannames van de wetgever, dat deelname aan de maatschappij via de reguliere arbeidsmarkt primaat heeft en dat de besproken hervormingen van de sociale zekerheid eigen regie voor mensen met een functiebeperking juist naderbij brengen, zijn namelijk betwistbaar - zeker als men de noden en behoeften van de mensen met de zwaarste verstandelijke en lichamelij-

62. Kamerstukken I 2019/20, 35213, Q; M. Willemsen, 'Met beperking baan vinden nu extra lastig', NRC Handelsblad 15 september 2020, Werk \& Geld, p. 9; B. Vollebregt, 'Hoogopgeleid en ook een handicap? Dan lever je in', Trouw 19 mei 2020, Economie, p. 15; T. Beukema, 'Versimpeling Wajongwet betekent vooral flink inleveren, armoede dus', Trouw 25 oktober 2019, Opinie, p. 20

63. M. Versantvoort en P. van Echtelt, ,'Synthese en aandachtspunten', in: P. van Echtelt et al, Eindevaluatie van de Participatiewet, Den Haag: Sociaal en Cultureel Planbureau 2019, p. 239-242, 245, 250-255; Van Echtelt 2019, p. 54, 57, 63, 86; Centraal Planbureau, Position paper: hoofdlijnennotitie loondispensatie participatiewet, Den Haag: Centraal Planbureau 2018, p. 3.

64. V. della Fina, 'Article 4 [general obligations]', in: V. della Fina, R. Cera en G. Palmisano (red.), The United Nations Convention on the Rights of Persons with Disabilities: A Commentary, Cham: Springer 2017, p. 145. 
ke beperkingen serieus neemt. Ook deze laatste groep moet namelijk volwaardig aan de maatschappij deel kunnen nemen en dient aldus behandeld te worden. ${ }^{65}$ Deze situatie kan naderbij gebracht worden door andere manieren van bijdragen, die niet (helemaal) op de reguliere arbeidsmarkt plaatsvinden, te herwaarderen. Hierbij kan men bijvoorbeeld denken aan het belonen van maatschappelijke activiteiten die nu onder de noemer vrijwilligerswerk vallen. ${ }^{66}$ Een andere belangrijke stap om een dergelijke volwaardige maatschappelijke deelname voor alle mensen met een functiebeperking te verwezenlijken, is ervoor zorgen dat de hiertoe noodzakelijke voorzieningen daadwerkelijk het karakter van een recht krijgen, in plaats van een gunst die maar al te vaak varieert, afhankelijk van de genade van de prevalente politieke wind. Deze twee voorstellen, de herwaardering van bijdragen buiten de reguliere arbeidsmarkt en een betrouwbare basis an voorzieningen voor mensen met een functiebeperking, kunnen dienen als beginpunt voor het dringende gesprek over de invulling van de plicht van de maatschappij om de volwaardige maatschappelijke deelname van al haar burgers met een functiebeperking afdoende te faciliteren.

66. G.B.M. Engbersen et al., Het betere werk: de nieuwe maatschappelijke opdracht, Den Haag: Wetenschappelijke Raad voor het Regeringsbeleid 2020, p. 138, 182-183; C. Huisman, 'In Almere krijgt het zorgbeleid een gezicht', de Volkskrant 19 februari 2018, Ten eerste, p. 14-15. 